\title{
Long-term follow-up results of patients with ADCK4 mutations who have been diagnosed in the asymptomatic period: effects of early initiation of CoQ10 supplementation
}

\author{
Mustafa Atmaca ${ }^{1}$, Bora Gülhan², Emine Atayar ${ }^{3}$, Aysun Karabay Bayazit ${ }^{4}$, Cengiz Candan ${ }^{5}$, \\ Mustafa Arıc1 ${ }^{6}$, Rezan Topaloğlu², Fatih Özaltın²,3,7 \\ ${ }^{2}$ Division of Pediatric Nephrology, ${ }^{1}$ Department of Pediatrics, ${ }^{3}$ Nephrogenetics Laboratory and ${ }^{6}$ Division of Nephrology, \\ Hacettepe University Faculty of Medicine, Ankara; ${ }^{4}$ Division of Pediatric Nephrology, Çukurova University Faculty \\ of Medicine, Adana; ${ }^{5}$ Division of Pediatric Nephrology, Istanbul Medeniyet University Faculty of Medicine, Istanbul; \\ ${ }^{7}$ Hacettepe University Center for Biobanking and Genomics, Ankara, Turkey. E-mail: fozaltin@hacettepe.edu.tr \\ Received: 8th October 2018, Revised: 18th February 2019, 25th April 2019, Accepted: 3rd July 2019
}

SUMMARY: Atmaca M, Gülhan B, Atayar E, Karabay Bayazıt A, Candan C, Arıcı M, Topaloğlu R, Özaltın F. Long-term follow-up results of patients with ADCK4 mutations who have been diagnosed in the asymptomatic period: effects of early initiation of CoQ10 supplementation. Turk J Pediatr 2019; 61: 657-663.

\begin{abstract}
$A D C K 4$-related glomerulopathy is a recently recognized clinical entity associated with insidious onset in young children and a high potential to progress to chronic kidney disease in adolescents. Early initiation of exogenous coenzyme Q10 (CoQ10) supplementation in the asymptomatic period could be protective on renal functions. In the present study, we aimed to investigate long-term follow-up of patients that we have diagnosed during the asymptomatic period and in whom we started CoQ10 treatment. We analyzed long-term effects of CoQ10 on proteinuria and estimated glomerular filtration rate (eGFR) in this patient population. A total of 8 patients ( 4 female, 4 male) from 6 different families were included. The mean age at diagnosis and at last visit were $16.8 \pm 11.2$ years and $20.7 \pm 11.7$ years, respectively. None of the patients had extrarenal system involvement. At the time of initiation of treatment; median eGFR was $107.8 \mathrm{ml} / \mathrm{min} / 1.73 \mathrm{~m}^{2}$, median proteinuria was $1008 \mathrm{mg} / \mathrm{m}^{2} /$ day. After a median follow-up period of $25.3 \pm 5.8$ months, median proteinuria decreased to $318.5 \mathrm{mg} / \mathrm{m}^{2} /$ day $(\mathrm{p}=0.03)$ and median eGFR remained stable at $99.6 \mathrm{ml} / \mathrm{min} / 1.73 \mathrm{~m}^{2}(\mathrm{p}=0.21)$. Coenzyme $\mathrm{Q} 10$ treatment is effective for reducing proteinuria and seems to be renoprotective.
\end{abstract}

Key words: Steroid-resistant nephrotic syndrome, ADCK4 mutation, CoQ10 treatment.

Glomerular proteinuria results from the disruption of the anti-proteinuric mechanism of the glomerular filtration barrier and is a hallmark of podocyte injury. Massive glomerular proteinuria is associated with nephrotic syndrome clinically characterized by hypoalbuminemia, edema and hyperlipidemia. Hereditary forms of proteinuria and nephrotic syndrome inevitably progress to chronic kidney disease (CKD) and end stage kidney disease (ESKD) requiring renal replacement therapy for survival. To date, several genes have been identified to cause proteinuria and nephrotic syndrome when mutated. ${ }^{1}$ Among them, mutations in genes encoding endogenous coenzyme Q10 (CoQ10) synthesis are of particular importance as exogenous supplementation of deficient CoQ10 may have therapeutic potential in this group of disorder. ${ }^{2}$ CoQ10 is a lipophilic, vitamin-like cellular

This study was presented at the 51th European Society For Paediatric Nephrology Congress, 3-6th October 2018, Antalya, Turkey. 
component that is endogenously synthesized in the mitochondria through many enzymatic steps each of which is regulated by a particular gene. ${ }^{3}$ We and others have recently introduced ADCK4-glomerulopathy resulted from the AarF Domain Containing Kinase-4 (ADCK4) gene mutations as an important novel differential diagnosis in adolescents with steroid resistant nephrotic syndrome and/or CKD of unknown origin, which may be amenable to treatment with exogenous supplementation of CoQ10., ${ }^{4,5}$ To test the efficacy of exogenous CoQ10 supplementation, we have recently conducted a study involving 28 patients with homozygous ADCK 4 mutation from 11 different families and have demonstrated that CoQ10 supplementation appears to be efficacious for reducing proteinuria and have suggested that this approach may be renoprotective. ${ }^{6}$ In that study, we have identified 8 apparently healthy individuals with $A D C K 4$ mutation through family screening in an asymptomatic proteinuria period and have initiated exogenous CoQ10 supplementation in an relatively early period. We have clearly demonstrated that CoQ10 supplementation reduced proteinuria significantly during a median follow-up duration of 11.5 (range 4-21) months while eGFR was preserved. However, it is not known if this early positive effect will be sustainable. In order to address this question, we aimed to investigate the long term follow-up of these asymptomatic patients and long-term effects of CoQ10 on disease course.

\section{Material and Methods}

\section{Patients}

This study included 8 apparently healthy patients from 6 different families who were diagnosed in an asymptomatic period with family screening of the index individuals with ADCK4 mutations. CoQ10 treatment was initiated with a dose of $20-30 \mathrm{mg} / \mathrm{kg} /$ day after the genetic diagnosis during the asymptomatic period. These patients were followed-up regularly by means of estimated glomerular filtration rate (eGFR) using Schwartz formula ${ }^{7}$ and urinary protein levels at 3-6 months intervals. For adult patients, eGFR was calculated with "modification of diet in renal disease" (MDRD) formula. ${ }^{8}$ Proteinuria was defined as $4-40 \mathrm{mg} / \mathrm{m}^{2} /$ hour of protein level in 24-hour collection. Nephrotic range proteinuria was defined as $>40 \mathrm{mg} / \mathrm{m}^{2} /$ hour urinary protein level. Chronic renal failure was defined as $<90 \mathrm{ml} / \mathrm{min} / 1.73 \mathrm{~m}^{2}$ of eGFR.

The study was approved by the ethics committee of Hacettepe University (17/27110). Written informed consent was obtained from the parents of all the patients.

\section{Statistical Analysis}

The research data was loaded and evaluated in the computer environment via"SPSS (Statistical Package for Social Sciences) for Windows 22.0 (SPSS Inc, Chicago, IL)". Descriptive statistics are presented as mean \pm standard deviation, median (interquartile range (IQR)), frequency distribution and percentage. The Wilcoxon Signed Ranks Test was used as a statistical method between two dependent samples. The relationship between the independent variables was assessed by independent samples T-test (Independent Samples T-test). Statistical significance level was accepted as $\mathrm{p}$ $<0.05$.

\section{Results}

\section{Patients' characteristics}

A total of 8 patients ( 4 male, 4 female) from 6 different families were evaluated. Patients \#2, $\# 3$ and \#4, \#5 are siblings. The mean age at diagnosis was $16.8 \pm 11.2$ years. The mean age of the patients at the last visit was $20.7 \pm 11.7$ years. All patients had homozygous mutations in $A D C K 4$. Four patients from 2 different families had c.1199dupA, 3 patients from 3 different families had c.293T > G and 1 patient had c.1339dupG mutations, respectively (Table I).

At the time of diagnosis, median eGFR was 107.8 (IQR; $94.2-132.1$ ) $\mathrm{ml} / \mathrm{min} / 1.73 \mathrm{~m}^{2}$ and median proteinuria was 1008 (IQR 281-1567) $\mathrm{mg} / \mathrm{m}^{2} /$ day. Mean albumin level at the time of diagnosis was $4.0 \pm 0.4 \mathrm{~g} / \mathrm{dl}$. None of the patients had extrarenal involvement at the time of treatment.

\section{Results of coenzymeQ10 treatment}

The mean CoQ10 dose of the patients during 
Table I. Characteristics of the Patients.

\begin{tabular}{|c|c|c|c|c|c|c|}
\hline $\begin{array}{l}\text { Patient's } \\
\text { number }\end{array}$ & LAB-ID/gender & $\begin{array}{l}\text { Age of } \\
\text { diagnosis } \\
\text { (years) }\end{array}$ & $\begin{array}{l}\text { Age at } \\
\text { last visit } \\
\text { (years) }\end{array}$ & $\begin{array}{l}\text { Clinical } \\
\text { feaures at } \\
\text { diagnosis }\end{array}$ & Consanguinity & Mutation \\
\hline 1 & PN6_II-2/F & 27 & 30 & $\mathrm{P}$ & yes & c.293T > G (p.L98R) (H) \\
\hline 2 & PN108_II-6/F & 2 & 5.2 & NP, h & yes & $\begin{array}{l}\text { c.1199dupA } \\
(\text { p.His400Glnfs*11) }(\mathrm{H})\end{array}$ \\
\hline 3 & PN108_II-7/M & 7 & 9.2 & $\mathrm{P}, \mathrm{h}$ & yes & $\begin{array}{l}\text { c.1199dupA } \\
(\text { p.His400Glnfs*11) (H) }\end{array}$ \\
\hline 4 & PN356_II-4/F & 7.7 & 12 & NP & yes & $\begin{array}{l}\text { c.1199dupA } \\
(\text { p.His400Glnfs*11) (H) }\end{array}$ \\
\hline 5 & PN356_II-5/M & 23.7 & 25 & $\mathrm{P}$ & yes & $\begin{array}{l}\text { c.1199dupA } \\
(\text { p.His400Glnfs*11) (H) }\end{array}$ \\
\hline 6 & PN1143_II-1/F & 9 & 19.3 & $\mathrm{NP}, \mathrm{h}$ & yes & c.293T $>$ G (p.L98R) (H) \\
\hline 7 & PN1199_II-3/M & 24 & 26 & NP & no & $\begin{array}{l}\text { c.1399dupG } \\
\text { (p.Glu447Glyfs10)(H) }\end{array}$ \\
\hline 8 & PN1262_I-3/M & 32.2 & 40 & $\mathrm{P}$ & yes & c.293 T>G (p.L98R) (H) \\
\hline
\end{tabular}

F; female, H; homozygous, h; microscopic hematuria, M; male, NP; nephrotic proteinuria P; proteinuria

follow-up period was $11.1 \pm 3.6 \mathrm{mg} / \mathrm{kg} /$ day. Two patients were started angiotensin converting enzyme inhibitor (ACEi) in addition to CoQ10 treatment at the same time. Patient \#6 was receiving angiotensin receptor blocker (ARB) (i.e. losartan) and ACEi 8 months before initiation of CoQ10 due to unavailability of CoQ10. Patient \#7 was receiving only ACEi for 3 months before CoQ10 due to unavailability of CoQ10 (Table II).

After a mean follow-up period of $25.3 \pm 5.8$ months, we showed that median proteinuria significantly decreased to 318.5 (IQR; 102.3$920) \mathrm{mg} / \mathrm{m}^{2} /$ day $(\mathrm{p}=0.03)$ when compared to those noted in the pre-treatment period, while median eGFR was stable at 99.6 (IQR; 61.3130.1 ) $\mathrm{ml} / \mathrm{min} / 1.73 \mathrm{~m}^{2}$ (compared to pretreatment value; $p=0.21$ ). Maximum response was observed at $6^{\text {th }}$ month after initiation of CoQ10 $(p=0.03)$. Mean serum albumin at the last visit was $3.9 \pm 0.4 \mathrm{~g} / \mathrm{dl}(\mathrm{p}=0.32)$. At the end of the follow-up period no hematuria was detected in any patient. For each patient, changes in proteinuria and eGFR according to time are shown in Figure 1 and 2, respectively.

Interestingly, in patient \#1, urinary protein level was $114 \mathrm{mg} / \mathrm{m}^{2} /$ day at the time of initiation of CoQ10 treatment. She stopped CoQ10 treatment during pregnancy and lactation. Then proteinuria progressively increased to $522 \mathrm{mg} / \mathrm{m}^{2} /$ day within 9 months. Re-institution of CoQ10 resulted in a decrease in urinary protein excretion to $343 \mathrm{mg} / \mathrm{m}^{2} /$ day at $6^{\text {th }}$ month after re-institution of CoQ10. During this period, eGFR was between 111$174 \mathrm{ml} / \mathrm{min} / 1.73 \mathrm{~m}^{2}$.

For the patient \#2, urinary protein level was $1605 \mathrm{mg} / \mathrm{m}^{2} /$ day, while eGFR was $137.4 \mathrm{ml} /$ $\mathrm{min} / 1.73 \mathrm{~m}^{2}$ at the time of initiation of CoQ10 treatment. Both enalapril and CoQ10 were initiated. On $6^{\text {th }}$ month, urinary protein level decreased to $97 \mathrm{mg} / \mathrm{m}^{2} /$ day with eGFR of 45.9 $\mathrm{ml} / \mathrm{min} / 1.73 \mathrm{~m}^{2}$. Enalapril was then stopped. The patient received CoQ10 irregularly between $17^{\text {th }}$ and $21^{\text {th }}$ months. On $24^{\text {th }}$ month, proteinuria increased to $1091 \mathrm{mg} / \mathrm{m}^{2} /$ day again while eGFR was $66 \mathrm{ml} / \mathrm{min} / 1.73 \mathrm{~m}^{2}$.

Patient \#4 had urinary protein level of $1589 \mathrm{mg} /$ $\mathrm{m}^{2} /$ day while eGFR was $102.1 \mathrm{ml} / \mathrm{min} / 1.73 \mathrm{~m}^{2}$ at the initiation of CoQ10. After CoQ10 and enalapril, proteinuria decreased to $786 \mathrm{mg} /$ $\mathrm{m}^{2} /$ day at $3^{\text {rd }}$ month while eGFR was $91.7 \mathrm{ml} /$ $\mathrm{min} / 1.73 \mathrm{~m}^{2}$. The patient had to decrease the dose of CoQ10 due to cost and shortage of the drug and then proteinuria increased to 1038 $\mathrm{mg} / \mathrm{m}^{2} /$ day within 6 months. The patient had continued irregular use of the drug and at the $30^{\text {th }}$ month of follow-up, proteinuria increased to $1707 \mathrm{mg} / \mathrm{m}^{2} /$ day with a significant decrease in eGFR (i.e. $27 \mathrm{ml} / \mathrm{min} / 1.73 \mathrm{~m}^{2}$ ). 


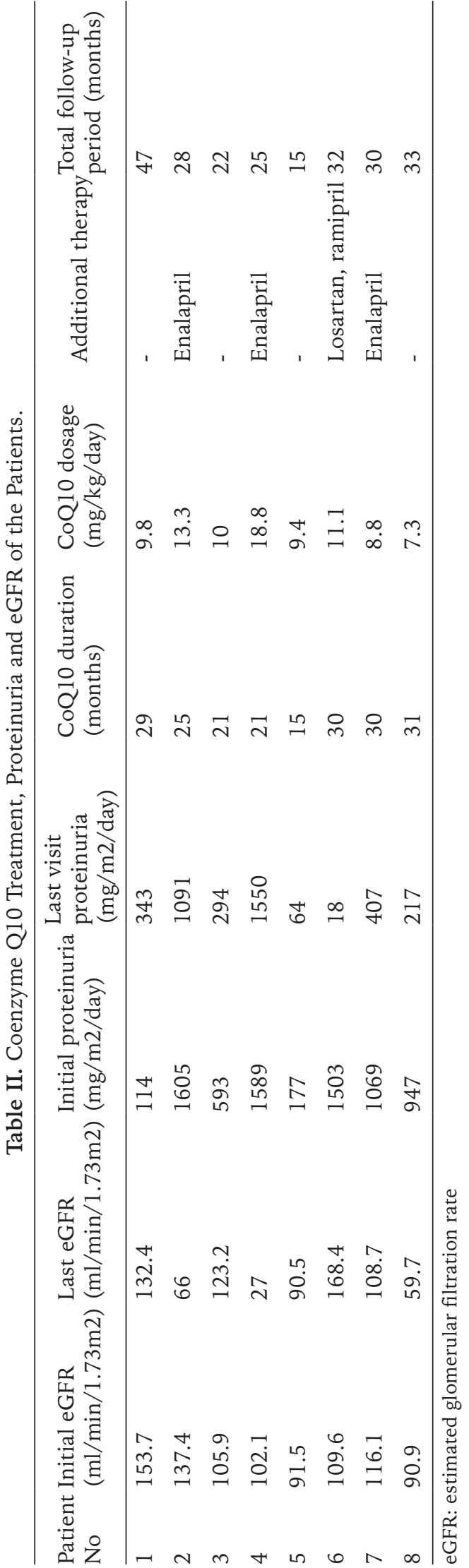

The rest of the patients received CoQ10 regularly at recommended doses and proteinuria progressively decreased while eGFR remained stable (Fig. 1 and 2).

\section{Discussion}

Efficacy of supplementation of exogeneous CoQ10 has been shown anecdotally in patients with various types of CoQ10 deficiencies including CoQ10 nephropathies. However, there is no study addressing whether supplementation of CoQ10 has a reno-protective potential if started in an asymptomatic period before irreversible renal damage is established. We and others have shown that ADCK4-related glomerulopathy, a CoQ10 nephropathy, is a progressive disorder and is one of the most important differential diagnosis in adolescent patients with CKD. ${ }^{6}$ The present study is the first to remove the curiosity regarding renoprotective potential of early initiation of CoQ10 supplementation in asymptomatic individuals with biallelic ADCK4 mutation. In our study, we clearly showed that exogenous CoQ10 treatment is beneficial for reducing proteinuria and preserving GFR given the fact that uninterrupted use of CoQ10 is related to sustained decrease in urinary protein level while GFR is preserved but deviation from the treatment is associated with increased urinary protein excretion and decreased GFR in patients with ADCK4related glomerulopathy.

The first link between CoQ10 and renal disease was established in 2000 by Rötig et al. ${ }^{9}$ who reported three affected siblings with CoQ10 deficiency in multiple tissues. The third sibling, elder sister, died at the age of 8 years after rapid neurological deterioration. Her younger brother and sister developed ESKD and renal transplantation was performed at the age of 8 and 9 years, respectively. Biochemical analysis revealed CoQ10 deficiency. These younger siblings were treated with oral CoQ10 (5 mg/kg/day), which resulted in substantial improvement in neurological status over a 3-year period. This observation was a milestone that supplementation of exogenous CoQ10 would be considered in CoQ10 deficiencies. ${ }^{9}$ Later on, Salviati et al. ${ }^{10}$ reported two siblings with CoQ2 


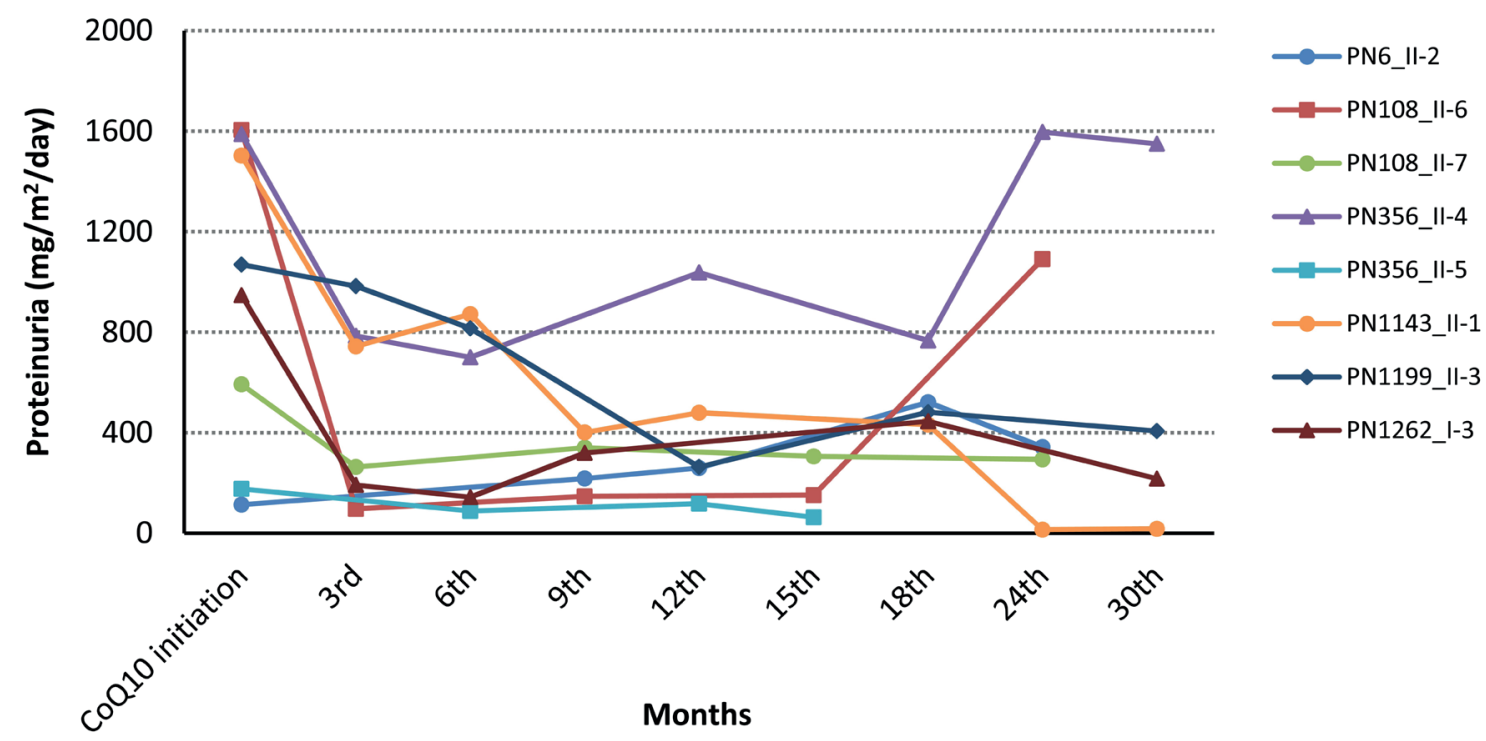

Fig. 1. Proteinuria of each patient during follow-up.
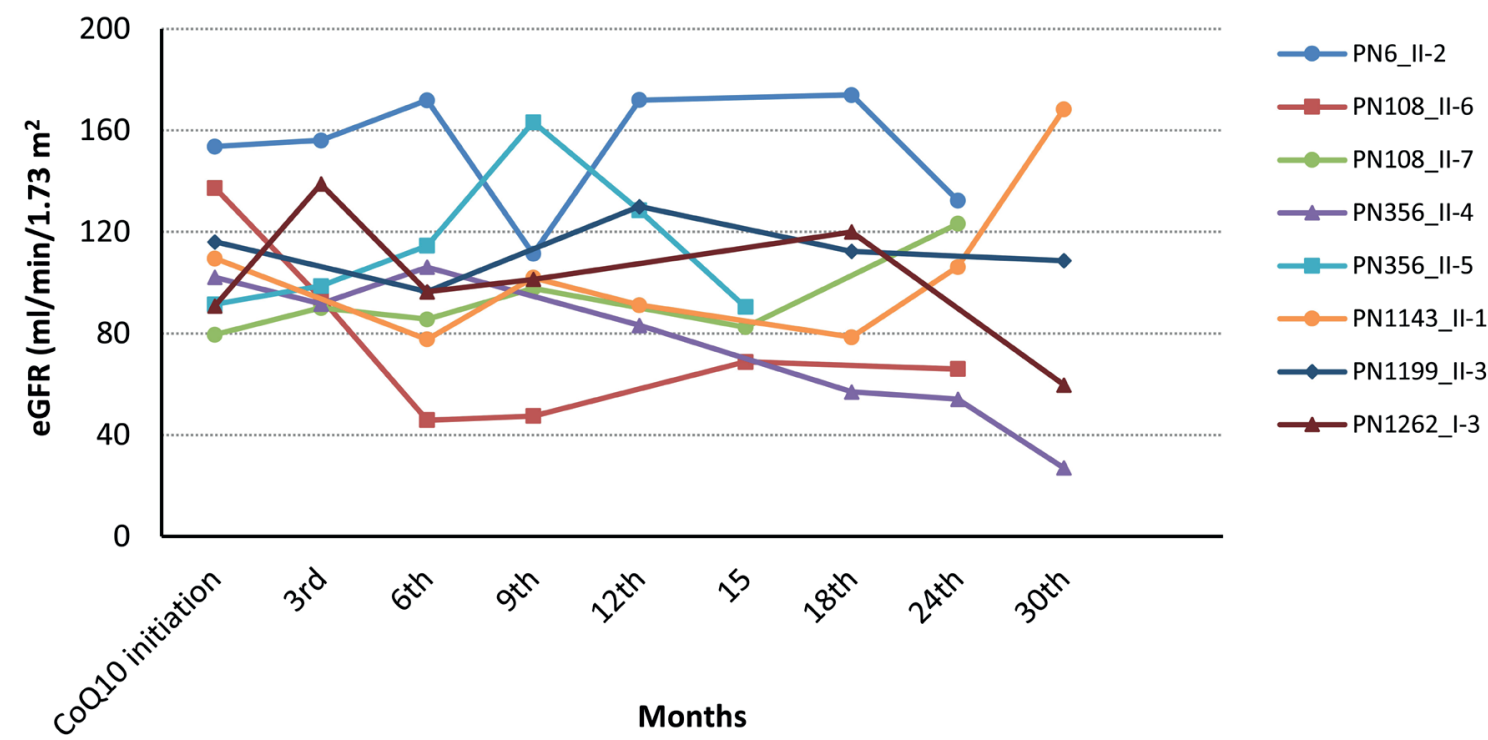

Fig. 2. eGFR of each patient during follow-up.

mutation with similar neurological findings and psychomotor regression. The proband presented with hypotonia, mild psychomotor delay, optic atrophy and proteinuria, which was associated with biopsy-proven focal and segmental glomerulosclerosis at 12 months of age. At age 18 months, peritoneal dialysis was initiated. Later he developed right hemiplegia, myoclonus and swallowing difficulties. After initiation of CoQ10, the neurological status of the child improved. Diomedi-Camessei et al. ${ }^{11}$ reported a 18-month-old boy with severe steroid resistant nephrotic syndrome. During follow-up, unilateral nephrectomy was performed due to uncontrolled anasarca and peritoneal dialysis was initiated. With CoQ10 supplementation, his neurological status remained normal for 8 months. These initial reports showed improvement in neurological status after oral CoQ10 supplementation. However, renal status was not affected by CoQ10 because these patients already had advanced kidney disease. Montini et al. ${ }^{12}$ reported a girl with COQ2 mutation in 
whom CoQ10 supplementation significantly decreased proteinuria and preserved renal functions. After these anecdotal reports, we and others showed the efficacy of CoQ10 in a larger group of patients with ADCK4-related nephropathy. In these studies, 3 patients have been reported to experience reduced proteinuria after initiation of CoQ10. ${ }^{4,5}$ Clinical effects of CoQ10 have also been supported by, in vitro studies, which have demonstrated that knockdown of ADCK4 in podocytes results in decreased migration and this is reversed by addition of CoQ10. ${ }^{5}$ Both clinical and in vitro observations support the idea that CoQ10 supplementation in patients with CoQ10 nephropathies would have a therapeutic potential. Indeed, we screened a large cohort of adolescent patients with SRNS and/or CKD of unknown origin for ADCK4 mutations and detected homozygous mutations in 28 individuals from 11 families. At the time of admission, all patients had albuminuria and 18 patients had CKD. CoQ10 supplementation was started once genetic diagnosis was established and proteinuria decreased without changing in GFR. ${ }^{6}$ At that study, we also identified 8 apparently asymptomatic patients during family screening and started CoQ10 therapy prior to deterioration of GFR. Initial results were favorable in terms of proteinuria and GFR. However, long-term effects of CoQ10 remained speculative. In the present study, we report longer followup results of these patients, which confirm that CoQ10 provides sustainable favorable effects during approximately 2 years of followup period. CoQ10 nephropathies are unique among hereditary nephropathies that may be amenable to treatment with exogenous CoQ10 supplementation. However, it should be noted that CoQ10 should be administered as soon as possible before irreversible damage occurs. As yet, no evidence-based study regarding optimum dose of CoQ10 is present. Therefore, we and others have given empirical doses..$^{2,4,6}$ Bioavailability of CoQ10 is poor and there is no correlation between its plasma and tissue levels. As CoQ10 works at inner mitochondrion, its amount reaching mitochondrion is much more important rather than its circulating level. Several commercially available pharmaceutical formulations are present in the market, however bioavailabilities are not comparable. This may explain interindividual differences in response to treatment. Montini et al. ${ }^{12}$ have suggested $30 \mathrm{mg} / \mathrm{kg} /$ day and massive proteinuria was controlled in approximately in 3 months. In our study, the mean CoQ10 dosage was approximately $11 \mathrm{mg} /$ $\mathrm{kg}$ /day. We observed maximum reduction of proteinuria at $6^{\text {th }}$ month. It, therefore, remains speculative whether higher CoQ10 dosage would yield additional benefits or if this would be due to difference in bioavailability of CoQ10 formulations that have been used in these studies. Nevertheless, it is advisable to wait for at least 6 months to observe response to treatment in patients with CoQ10 nephropathies. In addition, development of more efficient formulations that eliminates bioavailability problems and inter-individual differences is certainly needed to treat these patients more effectively. It should be noted that in our patient cohort, 4 patients received ACEi/ARB therapy in addition to CoQ10 during follow-up which may have contributed to the decrease in proteinuria in asymptomatic patients with $A D C K 4$ mutation. ${ }^{13}$

In conclusion, CoQ10 seems to have therapeutic and reno-protective effects in asymptomatic individuals with homozygous ADCK4 mutations. Therefore, genetic screening of asymptomatic individials in families with CoQ10 nephropathy is justified in this type of hereditary nephropathy to save the kidneys.

\section{Acknowledgment}

The research leading to these results has received funding from the European Community's Seventh Framework Programme (FP7/2007-2013) under grant agreement $n^{\circ}$ 2012-305608 (EURenOmics).

\section{REFERENCES}

1. Wang F, Zhang Y, Mao J, et al. Spectrum of mutations in Chinese children with steroid-resistant nephrotic syndrome. Pediatr Nephrol 2017; 32: 1181-1192.

2. Ozaltin F. Primary coenzyme Q10 (CoQ10) deficiencies and related nephropathies. Pediatr Nephrol 2014; 29: 961-969.

3. Desbats MA, Lunardi G, Doimo M, Trevisson E, Salviati L. Genetic bases and clinical manifestations of coenzyme Q10 (CoQ 10) deficiencies. J Inherit Metab Dis 2015; 38: 145-156. 
4. Korkmaz E, Lipska-Ziętkiewicz BS, Boyer O, et al; PodoNet Consortium. ADCK4-associated glomerulopathy causes adolescence-Onset FSGS. J Am Soc Nephrol 2016; 27: 63-68.

5. Ashraf S, Gee HY, Woerner S, et al. ADCK4 mutations promote steroid-resistant nephrotic syndrome through CoQ10 biosynthesis disruption. J Clin Invest 2013; 123: 5179-5189.

6. Atmaca M, Gulhan B, Korkmaz E, et al. Follow-up results of patients with ADCK4 mutations and the efficacy of CoQ10 treatment. Pediatr Nephrol 2017; 32: 1369-1375.

7. Schwartz GJ, Muñoz A, Schneider MF, et al. New equations to estimate GFR in children with CKD. J Am Soc Nephrol 2009; 20: 629-637.

8. Levey AS, Coresh J, Greene $\mathrm{T}$, et al; Chronic Kidney Disease Epidemiology Collaboration. Using standardized serum creatinine values in the modification of diet in renal disease study equation for estimating glomerular filtration rate. Ann Intern Med 2006; 145: 247-254.
9. Rötig A, Appelkvist EL, Geromel V, et al. Quinoneresponsive multiple respiratory-chain dysfunction due to widespread coenzyme Q10 deficiency. Lancet 2000; 356: 391-395.

10. Salviati L, Sacconi S, Murer L, et al. Infantile encephalomyopathy and nephropathy with CoQ10 deficiency: a CoQ10-responsive condition. Neurology 2005; 65: 606-608.

11. Diomedi-Camassei F, Di Giandomenico S, Santorelli FM, et al. COQ2 nephropathy: a newly described inherited mitochondriopathy with primary renal involvement. J Am Soc Nephrol 2007; 18: 2773-2780.

12. Montini G, Malaventura C, Salviati L. Early coenzyme Q10 supplementation in primary coenzyme Q10 deficiency. N Engl J Med 2008; 358: 2849-2850.

13. Stotter BR, Ferguson MA. Should ACE inhibitors and ARBs be used in combination in children? Pediatr Nephrol 2019; 34: 1521-1532. 